\title{
Optimal Acquisition Strategies in Unknown Territories
}

\author{
Onur Koska* \\ Department of Economics \\ University of Otago
}

\author{
Frank Stähler ${ }^{\dagger}$ \\ Department of Economics \\ University of Würzburg
}

August 2009

\begin{abstract}
This paper investigates the optimal acquisition strategy of a multinational firm willing to buy out one incumbent firm under incomplete information. There is more than one incumbent firm. Hence the multinational firm has several acquisition strategies: first, it can offer a proposal for a buy-out to only one incumbent firm of its choice, and it stays out of the market if this particular firm rejects its offer; second, it can offer a proposal to a firm that it randomly chooses, and, if this offer is rejected, then it can make another offer to the other incumbent firm; or, third, it can simultaneously offer the same proposal to all incumbent firms. Our main result shows that making sequential offers is the optimal acquisition strategy within the available take-it-or-leave-it acquisition strategies.
\end{abstract}

Keywords: Multinational Firms; Acquisition; Uncertainty; Cournot Competition.

JEL Classification: C72; D21; D82; F23; L13.

*Corresponding Author. Department of Economics, University of Otago, PO Box 56, Dunedin 9054, New Zealand. Email: onur.koska@otago.ac.nz. Tel: +64 34798152. Fax: +64 34798174 .

${ }^{\dagger}$ Department of Economics, University of Würzburg, Sanderring 2, D-97070 Würzburg, Germany. Email: frank.staehler@uni-wuerzburg.de. 


\section{Introduction}

Cross-border mergers and acquisitions are quantitatively significant phenomena. According to UNCTAD's (2006) report, in the period 1999-2001 and since 2005, more than six thousand cross-border mergers and acquisitions were undertaken annually. This number only includes successful mergers; the total number of merger proposals, in the same period, would have been a much larger number.

Why do merger/acquisition proposals fail? One reason is that a target firm often has private information on its worth, and that negotiations cease once either party realizes that they will not be able to agree on the sale price. However, a target firm's reservation sale price is influenced by the bidding firm's acquisition strategy. Therefore, the bidding firm's choice of its acquisition strategy is crucial for a successful merger/acquisition proposal.

This study investigates the optimal acquisition policy of a foreign firm in an uncertain environment. We restrict our attention to horizontal investment and consider a foreign firm intending to enter a pre-determined, single host country market. In order to enter the market, the foreign firm has to acquire a local firm. We assume that there are two local target firms in the market. The foreign firm does not know either firm's cost of production. Each local firm knows its own and the foreign firm's production cost, but not the other local firm's production cost. Hence, we analyze the firms' behavior in a two-stage Bayesian game. In the first stage, the foreign firm makes some acquisition offers to local firms. In the second stage, the Cournot duopoly game takes place. In our model, uncertainty persists even when firms compete à la Cournot, but we allow all firms to update their beliefs about their rivals' production cost with any relevant information revealed at the acquisition stage of the game.

The focus of the paper is to explore the optimal acquisition strategy of a foreign firm under incomplete information and to show how different acquisition strategies influence the outcome of a merger proposal. Under 
complete information, the foreign firm would be able to estimate precisely how much it should offer each target firm to make each of these firms indifferent between acceptance and rejection. Incomplete information, however, weakens its bargaining power. Since it does not know the target firms' production cost, it has to take into account that a too low offer may not make any target firm accept the offer. Alternatively, it should not make an excessive offer to either of the target firms. Furthermore, its acquisition strategy should be able to gain some information also from the rival-to-be in order to improve its competitive position in the Cournot game.

The foreign firm can choose the optimal acquisition strategy from several take-it-or-leave-it acquisition strategies. For instance, the foreign firm may make an offer only to a firm of its choice which we refer to as the one offer policy. Alternatively, it can make sequential offers such that it randomly picks one of the two local target firms and makes an offer as in the case of one offer to one firm. If this firm rejects the offer, the foreign firm will make another acquisition offer to the other local firm which is the main difference between the one offer policy and sequential offers. Furthermore, the foreign firm can simultaneously make a merger proposal to both firms which is the case of simultaneous offers. In this case, if both firms accept the offer, it randomly picks one of them. If neither firm accepts the offer, the foreign firm will stay out of the market.

Our main result is that making sequential offers is the optimal acquisition strategy within the set of available take-it-or-leave-it acquisition strategies. It has the right balance such as it provides the foreign firm with a fair probability of acceptance and some information about the rival firms' profitability. Furthermore, the foreign firm does not pay an excessive acquisition price. The one offer policy is the least preferred acquisition strategy, although it is the most common approach in the literature on mergers and acquisitions. In the one offer policy, the foreign firm relies only on one firm's decision. If this firm rejects the acquisition offer, the foreign firm stays out of the market. Moreover, the one offer policy does not provide the foreign firm with any useful information about the other 
firm's production cost.

We identify three effects determining the relative profitability of all acquisition strategies: a revelation effect, a competition effect and a risk component. The local firms signal their profitability by their acceptance/rejection of a particular offer, which we refer to as the revelation effect. We show that the revelation effect increases a firm's profit when it successfully signals that it is a low-cost firm, and it decreases the profit of the firm observing a low-cost rival. A local firm receiving an offer makes its decision depending on its rejection profit. It may be the case that it competes against the most efficient firm, the foreign firm, when it rejects an offer, which we refer to as the competition effect. If a local firm is certain that it will compete against the other local firm after having rejected the foreign firm's offer, there will be no competition effect and its rejection profit will increase in its signal as the other firm will observe this firm rejecting the investor's offer and will update its priors accordingly. Finally, a local firm may compete against the foreign firm even if it accepts an offer, which we refer to as the risk component. All effects are consequences of incomplete information.

Most of the studies in the literature on mergers and acquisitions concentrate on firms' incentives to merge under complete information. For instance, Salant et al. (1983) study the profitability of a merger of a subset of firms competing in quantities. In their model, all firms have symmetric, identical, constant marginal cost. They also assume that if firms agree to merge, the merged entity will have the same, constant marginal cost; that is, the merged entity will have the same size as its constituent firms. Hence, a merger does not lead merging firms to reduce costs, but just to reduce competition in the industry. They find that firms have no incentive to merge unless the merger includes 80 per cent of all firms in the industry.

Stigler (1950) argues that firms may benefit from not participating in a merger when some other firms are merging..$^{1}$ In fact, if a merger

\footnotetext{
${ }^{1}$ Hennessy (2000) replaces Salant et al.'s (1983) linear demand assumption with a convex demand and shows that merging firms benefit from the reduction in competition
} 
does not enable merging firms to combine their productive assets and generate efficiency gains, it may not be profitable if the output of the merged entity decreases, which increases the industry price ${ }^{2}$ Following the price increase, non-colluding firms may increase their output so as to free ride on increasing industry profit. In contrast to Salant et al.'s (1983) study, Perry and Porter (1985) show that firms may have incentives to merge and there is no need to include 80 per cent of firms in the industry. They allow the merged firm to utilize firm-specific assets of its partner firms and so to increase output at a given average cost. Furthermore, they find that the price increase may often be sufficient to compensate for the output reduction of the merged firm. They argue that if the merged firm is twice as large as each partner, the output reduction is not as severe. All these studies help to understand under which conditions firms may be willing to merge without uncertainty. But, they all fail to explain firms' willingness to merge under some uncertainty.

Firms often make merger decisions under incomplete information which not only alters their incentives to merge, but also influences the probability that a merger occurs as well as the probability that an established merger succeeds $3^{3}$ There is a high rate of merger failures; see, for example Banal-Estañol and Seldeslachts (2005). We also often observe that merger proposals fail, especially when there is incomplete information. It is not only about uncertainty, but using inadequate acquisition strategies as well. In fact, a proper acquisition strategy is important for a

even when there are no cost efficiencies. By allowing for product differentiation and considering Bertrand competition, Deneckere and Davidson (1985) also show that mergers of any size are profitable.

${ }^{2}$ In a Cournot oligopoly, Farrell and Shapiro (1990) investigate necessary and sufficient conditions for horizontal mergers to raise price. They show that a merger raises price if it does not generate synergies between the merging firms.

${ }^{3}$ Qiu and Zhou (2006) study international mergers under asymmetric information such that local firms have better information on market demand than foreign firms do. They argue that this information asymmetry generates incentives for firms from different countries to merge. Banal-Estañol (2007) also finds that uncertainty may increase merger incentives and decrease free-riding effects.

${ }^{4}$ Zhou (2008) studies endogenous mergers under cost uncertainty and shows that mergers occur if and only if uncertainty is large. 
successful merger/acquisition proposal. However, in the existing literature on mergers and acquisitions, firms' acquisition strategies and bargaining processes are often oversimplified either by implicitly or explicitly assuming a single offer to a single target only, or by employing an exogenous bargaining process.$^{5}$ Hence, this study contributes to the existing literature by endogenizing the bargaining process and analyzing firms' optimal acquisition strategies under incomplete information.

Our study is closely related to Hviid and Prendergast (1993). They examine the influence of a failing merger proposal on firms' ex post profitability. They consider a potential merger between two firms and assume that the firm making the merger proposal does not know the target firm's profitability. The merger proposal fails if the offer is less than the target firm's profit given rejection (i.e., its profit if it rejects the offer and competes against the bidding firm). They show that an unsuccessful merger proposal may increase the target firm's profit. By rejecting the merger proposal, the target firm signals that it is de facto a low-cost firm. The firm observing the low-cost rival updates its priors, and hence expects less profits ${ }^{6}$ In their study, the firm making a merger proposal has no choice except to make a single offer to the existing target firm because there is only one target by assumption $\sqrt{7}$ In our study, however, we allow the foreign firm to choose from various acquisition strategies. Each acquisition strategy has important implications for both the foreign firm's merger

\footnotetext{
${ }^{5}$ The literature on endogenous mergers includes alternative approaches such as simultaneous bidding as in Kamien and Zang $(1990,1991)$, sequential bidding as in Kamien and Zang (1993), and sequential voting on mergers as in Rodrigues (2001) and Zhou (2008).

${ }^{6}$ Dassiou and Holl (1996), however, consider Bertrand competition and allow for product differentiation, and show that information revealed by the target firm rejecting the merger proposal negatively affects not only the bidding firm, but the target firm as well.

${ }^{7}$ Assuming a single target firm simplifies the analysis substantially, yet rules out the other possible acquisition strategies (i.e., bargaining sequentially or simultaneously with more than one target firm). Moreover, as discussed later, when a firm adopts the one offer policy to acquire a target firm - not because it is willing to, but because there is only one target firm - there will be no risk component and/or competition effect which may have helped this firm to reduce the reservation sale prices of the target firm(s) and/or to increase the probability of acquiring a target.
} 
proposal and the target firms' willingness to accept an offer, which we scrutinize in this study.

The remainder of the paper is organized as follows: we introduce the model and discuss the one offer policy in Section 2. In Section 3, we scrutinize the case of sequential offers. In Section 4 , we solve the model for the case of simultaneous offers. We conclude in Section 5. For convenience, we have relegated some proofs and technical details to the Appendix.

\section{The model}

We consider a market which is served by two firms, labeled 1 and 2 . Consumers in this market have quasi-linear preferences which give rise to the inverse demand function $p=a-\left(q_{1}+q_{2}\right)$ where $p$ denotes the equilibrium price and $q_{1}$ and $q_{2}$ are the respective outputs of the two firms. We assume that $a>2$ which guarantees that both firms always want to produce in equilibrium. The production costs are private information of the firms, and both firms draw their cost from the uniform distribution $F(c)=c$; hence, production costs are distributed between 0 and unity. Firms compete by quantities.

A foreign firm considers the acquisition of one of these firms in order to enter the market. If the foreign firm successfully acquires a firm, it will be able to use its technology in this market (Barros 1998; Borek et al. 2004). We normalize the foreign firm's production cost to zero which is common knowledge amongst all firms. Hence, the foreign firm is technologically superior, and its primary interest is to enter the market by acquiring a firm. In its best-case scenario under complete information, both host country firms have sufficiently high production costs; hence the foreign firm is able to buy out a firm relatively cheaply, and also compete against a weak rival. Under incomplete information, it has to take into account that neither firm may accept an offer nor reveal their production cost truthfully.

Before we turn to acquisition strategies, we have to determine the 
optimal outputs and maximized profits in this market. To this end, we will be as general as possible and we allow that an acquisition strategy signals a certain range or even the exact cost of one or both competitors in this market. Consider firm 1 which maximizes its expected profit $\Pi_{1}=$ $\left(a-q_{1}-E_{1}\left(q_{2}\right)-c_{1}\right) q_{1}$, where $q_{1}$ denotes firm 1's output and $E_{1}\left(q_{2}\right)$ is firm 1's expectation of firm 2's output. A similar expression holds for firm 2. The first-order conditions imply optimal output levels:

$$
\begin{aligned}
& q_{1}=\frac{a-E_{1}\left(q_{2}\right)-c_{1}}{2}, \\
& q_{2}=\frac{a-E_{2}\left(q_{1}\right)-c_{2}}{2} .
\end{aligned}
$$

Firm 1 does not know firm 2's cost, but it correctly anticipates the optimal behavior of the rival firm (i.e., $E_{1} E_{2}\left(q_{1}\right)=E_{2}\left(q_{1}\right)$ and $E_{2} E_{1}\left(q_{2}\right)=$ $\left.E_{1}\left(q_{2}\right)\right) .8$ Let $E_{1}\left(c_{2}\right)$ denote firm 1's expectation of firm 2's cost; similarly, $E_{2}\left(c_{1}\right)$ is firm 2's expectation of firm 1's cost. Note that $E_{2}\left(c_{1}\right)=E_{1}\left(c_{2}\right)=$ $1 / 2$ only if no information has been revealed during the acquisition stage which should warrant a Bayesian update. Accordingly, firm 1 anticipates that

$$
E_{1}\left(q_{2}\right)=\frac{a-E_{1} E_{2}\left(q_{1}\right)-E_{1}\left(c_{2}\right)}{2}=\frac{a-\frac{a-E_{2} E_{1}\left(q_{2}\right)-E_{2}\left(c_{1}\right)}{2}-E_{1}\left(c_{2}\right)}{2}
$$

which leads to

$$
\begin{aligned}
& E_{2}\left(q_{1}\right)=\frac{a+E_{1}\left(c_{2}\right)-2 E_{2}\left(c_{1}\right)}{3}, \\
& E_{1}\left(q_{2}\right)=\frac{a+E_{2}\left(c_{1}\right)-2 E_{1}\left(c_{2}\right)}{3} .
\end{aligned}
$$

Substituting (2) back into (1) yields the optimal outputs as a function of firm-specific and expected costs which are given by equation (3):

$$
\begin{aligned}
& q_{1}=\frac{2 a-E_{2}\left(c_{1}\right)+2 E_{1}\left(c_{2}\right)-3 c_{1}}{6}, \\
& q_{2}=\frac{2 a-E_{1}\left(c_{2}\right)+2 E_{2}\left(c_{1}\right)-3 c_{2}}{6} .
\end{aligned}
$$

\footnotetext{
${ }^{8} E_{i} E_{j}\left(q_{i}\right)$, for any $i \neq j$, is firm $i$ 's anticipation of firm $j$ 's expectation of firm $i$ 's output.
} 
Note that $a>2$ guarantees that outputs are positive even if $E_{-i}\left(c_{i}\right)=$ $c_{i}=1$ and $E_{i}\left(c_{-i}\right)=0$ where $i=1,2$. Since the first-order conditions imply that $p-c_{i}=-p^{\prime} q_{i}=q_{i}$, we can also derive the expected profits:

$$
\begin{aligned}
& \Pi_{1}^{*}=\left(\frac{2 a-E_{2}\left(c_{1}\right)+2 E_{1}\left(c_{2}\right)-3 c_{1}}{6}\right)^{2}, \\
& \Pi_{2}^{*}=\left(\frac{2 a-E_{1}\left(c_{2}\right)+2 E_{2}\left(c_{1}\right)-3 c_{2}}{6}\right)^{2} .
\end{aligned}
$$

In equation (4), $\Pi_{1}^{*}$ and $\Pi_{2}^{*}$ are firm 1's and firm 2's expected profits in equilibrium, respectively. Note that $c_{1}$ and $c_{2}$ are firm 1's and firm 2's realized production costs. As is clear in equation (4), a firm's expected profit is positively related to its expectation of its rival's cost and is negatively related to the rival firm's expectation of its own cost. Hence, if the rival firm reveals that it is a low-cost firm, the expected profit of the other firm decreases, ceteris paribus. Similarly, if a firm reveals that it is a low-cost firm, its expected profit increases, ceteris paribus, as the other firm updates its beliefs. ${ }^{9}$

We use the above model to discuss first the simplest acquisition strategy of the foreign firm: one acquisition offer to only one of the two firms - say, firm 1. If firm 1 accepts the offer, the deal is done and firm 1the foreign firm-produces in this market with zero cost. Hence, firm 2 observes the acquisition and updates its beliefs about firm 1's cost such that $E_{2}\left(c_{1}\right)=0$. Firm 1 - the acquired firm - does not learn anything about firm 2's productivity so that $E_{1}\left(c_{2}\right)=1 / 2$. According to expressions (3) and (4), the expected profits are equal to

\footnotetext{
${ }^{9}$ Suppose that firm 1 and firm 2 are the only firms in the market as is the case in Hviid and Prendergast (1993). According to their model, firm 1 is the bidding firm and firm 2 is the target firm. Firm 1 does not know firm 2's production cost; however its own production cost is common knowledge and normalized to zero (i.e., $E_{2}\left(c_{1}\right)=$ $\left.c_{1}=0\right)$. They show that if firm 1's merger proposal fails and it learns that firm 2 is a low-cost firm, its expected profit will decrease as is obvious in equation (4) in our model. According to the main result of Hviid and Prendergast (1993), the target firm's expected profit increases following a failed merger proposal. This result is also obvious in equation (4) as the update of the bidding firm's beliefs about the target firm's production cost means $E_{1}\left(c_{2}\right)$ decreases, which increases $\Pi_{2}^{*}$.
} 


$$
\begin{aligned}
& \Pi_{1}^{*}=\left(\frac{2 a+1}{6}\right)^{2}, \\
& \Pi_{2}^{*}=\left(\frac{2 a-\frac{1}{2}-3 c_{2}}{6}\right)^{2} .
\end{aligned}
$$

If firm 1 rejects the offer, no acquisition takes place and we might be tempted to conclude that the game is the same as if no offer had been made. However, this is not true as the rejection itself conveys information to the other firm as long as the offer is not trivial such that it is accepted or rejected by any type.

Let $\gamma \in[0,1]$ denote the type of firm, which is indifferent between acceptance and rejection of this one offer made to this type. In equilibrium, it should be true that all firms with a higher (lower) production cost than $\gamma$ should accept (reject) this offer. We determine $\gamma$ below; it leads firm 2 to update its beliefs such that $E_{2}\left(c_{1}\right)=\gamma / 2 \leq 1 / 2$ because we will show that only more efficient firms will reject the offer. Firm 1 has no reason to update its beliefs; therefore $E_{1}\left(c_{2}\right)=1 / 2$. Accordingly, the expected profits are given by equation (6):

$$
\begin{aligned}
& \Pi_{1}^{*}=\left(\frac{2 a-\frac{\gamma}{2}+1-3 c_{1}}{6}\right)^{2}, \\
& \Pi_{2}^{*}=\left(\frac{2 a-\frac{1}{2}+\gamma-3 c_{2}}{6}\right)^{2} .
\end{aligned}
$$

Note that $\Pi_{1}^{*}$ decreases with $c_{1}$ which confirms our sorting assumption that bad (good)-type firms accept (reject) the offer ${ }^{10}$ Equation (6) also allows us to determine the critical type, $\gamma$; in equilibrium, the critical type is indifferent between acceptance and rejection of the investor's offer. Let $\phi$ denote the foreign firm's offer to firm 1 which will be equal to firm 1's

\footnotetext{
${ }^{10} \mathrm{~A}$ bad (good)-type firm refers to the firm operating with a higher (lower) production cost than the production cost of the firm which is indifferent between acceptance and rejection of the investor's offer.
} 
profit in the case of acceptance. This profit must be equal to the rejection profit, denoted $\Pi_{1}^{*}$, given by equation (6a) where $c_{1}=\gamma$ in equilibrium, such that

$$
\phi(\gamma)=\left(\frac{2 a-\frac{\gamma}{2}+1-3 \gamma}{6}\right)^{2}=\left(\frac{4 a+2-7 \gamma}{12}\right)^{2}
$$

This indifference condition immediately specifies the acquisition offer of the foreign firm as a function of the types of the firms which will reject the offer. Clearly, $\phi$ decreases with $\gamma$. Furthermore,

$$
\phi(0)=\left(\frac{2 a+1}{6}\right)^{2}>\phi(1)=\left(\frac{4 a-5}{12}\right)^{2} .
$$

$\phi(0)$ is the compensation which makes the lowest-cost firm indifferent between acceptance and rejection (and thus any firm will accept this offer). The foreign firm may want to play safe and make a completely inclusive offer, $\phi(0)$, to one firm of its choice. As a result, it acquires this firm with certainty. However, the cost of playing safe is substantially high. Alternatively, the foreign firm can make a completely exclusive offer, $\phi(1)$, that is, the compensation which makes the highest-cost firm indifferent between rejection and acceptance (and thus no firm will accept this offer).

We are now ready to scrutinize the optimal one offer policy. What is the expected profit of the foreign firm? The foreign firm has to balance an increased chance of acceptance against the cost of a higher offer. Let $\Pi_{0}^{\gamma}$ denote the expected profit of the investor which we can write as a function of $\gamma$ :

$$
\Pi_{0}^{\gamma}(\gamma)=(1-\gamma)\left(\left(\frac{2 a+1}{6}\right)^{2}-\left(\frac{4 a+2-7 \gamma}{12}\right)^{2}\right) .
$$

Note that $\Pi_{0}(0)=0$. The first-order condition is given by equation (9):

$$
\frac{\partial \Pi_{0}^{\gamma}(\gamma)}{\partial \gamma}=\frac{7}{144}(4+8 a(1-2 \gamma)-\gamma(22-21 \gamma))=0
$$

which leads us to 
Lemma 1 In the one offer policy, the offer is neither completely inclusive nor completely exclusive.

Proof.

$$
\begin{aligned}
& \left.\frac{\partial \Pi_{0}^{\gamma}(\gamma)}{\partial \gamma}\right|_{\gamma=0}=\frac{7}{36}(2 a+1)>0 \\
& \left.\frac{\partial \Pi_{0}^{\gamma}(\gamma)}{\partial \gamma}\right|_{\gamma=1}=\frac{7}{6}\left(\frac{1}{8}-\frac{a}{3}\right)<0 \text { because } a \geq 2
\end{aligned}
$$

From equation (9), we can derive a closed form solution for the optimal rejection rate, denoted by $\gamma^{*}$ :

$$
\gamma^{*}=\frac{1}{21}(8 a+11-\sqrt{8 a(8 a+1)+37}) .
$$

The optimal rejection rate given by equation 10 determines the foreign firm's offer in equilibrium. We can express the exact functional form of the equilibrium offer by substituting equation (10) into equation (7). In Figure 1, we illustrate the probability of acceptance when the foreign firm makes this offer to only one of the two firms.

As is clear from Figure 1, the probability of acceptance ranges between 0.50 and 0.55 and is convex in market size, $a$. The larger the market size, the smaller the probability of acceptance. We next show that the foreign firm can do better by making sequential offers.

\section{Sequential offers}

In the previous section, we determined the optimal acquisition offer to only one of the two firms. In the one offer policy, the investor does not make any other offer following a firm's rejection, but it stays out of the market. This is the most common approach in the literature on mergers and acquisitions. This approach is intuitive only in markets with a single 


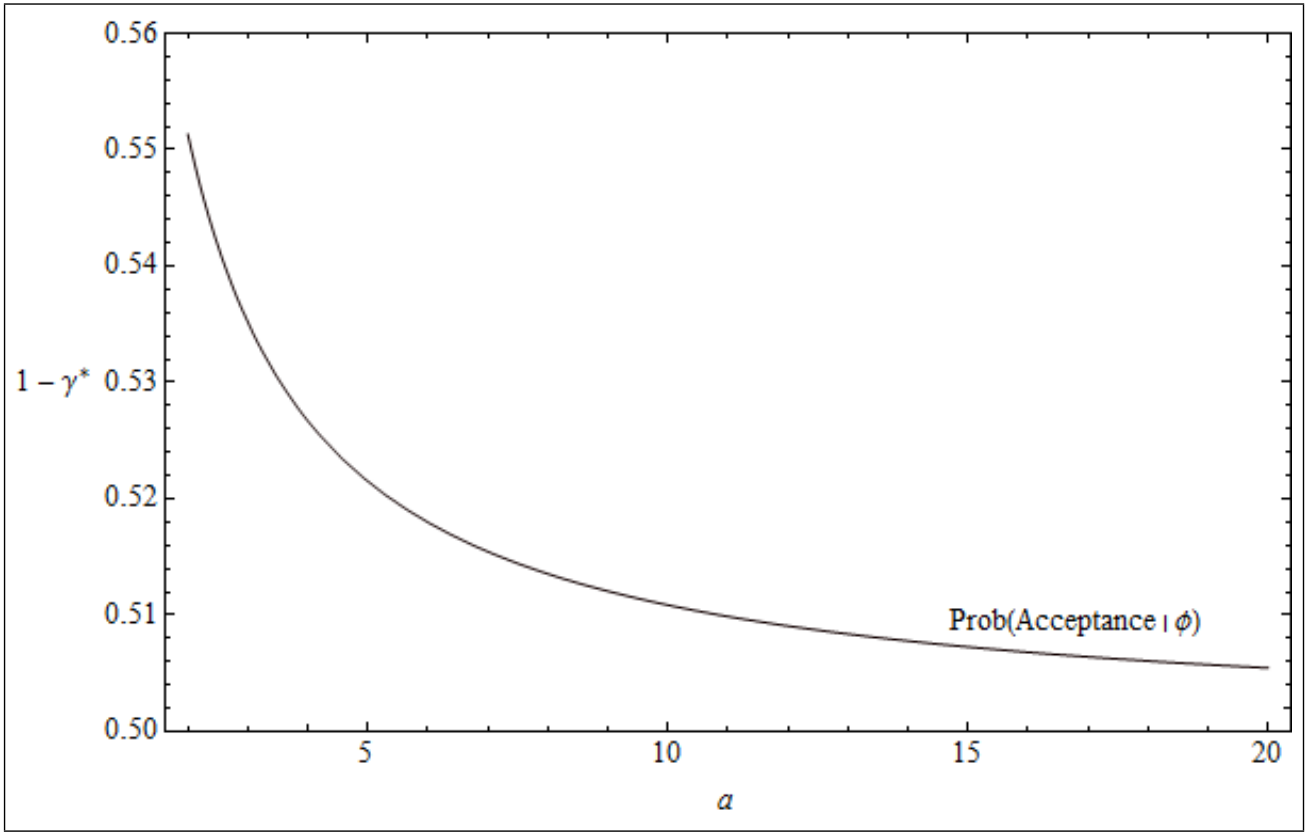

Figure 1: The Probability of Acceptance (One Offer Policy).

incumbent - target - firm. However, the investor may have been interested in more than one target - the market that the investor wants to enter may have more than one incumbent firm. Instead of staying out of the market after having its initial offer rejected by one target - the investor makes zero profit if it stays out of the market - the investor may want to make another offer to the other local firm. ${ }^{11}$ Thus, we now turn to the case that the investor makes sequential offers. In this case, the foreign firm randomly picks one of the two local target firms and makes an offer as in the one offer policy.

Let the foreign firm pick firm 1 and make the first offer to this firm. Let $\phi_{1}$ denote the foreign firm's offer. If firm 1 accepts this offer, firm 1 is acquired by the foreign firm, which will produce in this market with zero cost. Hence, firm 2 observes the acquisition and updates its beliefs

\footnotetext{
${ }^{11}$ For simplicity, we assume that the time delay is negligible in such a situation. Moreover, there is no cost of making an offer. Hence, the investor would lose nothing by making another offer to any other firm, but could benefit in the case of a successful offer.
} 
about firm 1's cost such that $E_{2}\left(c_{1}\right)=0$. The foreign firm does not learn anything about firm 2's productivity so that $E_{1}\left(c_{2}\right)=1 / 2$. Accordingly, the expected profits are given by equation (11):

$$
\begin{aligned}
& \Pi_{1}^{*}=\left(\frac{2 a+1}{6}\right)^{2}, \\
& \Pi_{2}^{*}=\left(\frac{2 a-\frac{1}{2}-3 c_{2}}{6}\right)^{2} .
\end{aligned}
$$

If firm 1 rejects the offer, the foreign firm makes another offer to the other firm, which is the main difference between the one offer policy and sequential offers. In the case of one offer, the local firm receiving an offer knows that if it rejects the offer, it will compete against the other local firm with certainty. In the case of sequential offers, there is a chance that the other firm accepts the investor's offer, and that the firm receiving and rejecting the first offer competes against the most efficient firm - the foreign firm. Hence, the local firm's expected profit in the case of rejection is lower.

Let $\gamma_{1}$ denote the type of the firm which is indifferent between acceptance and rejection of the offer, $\phi_{1}$. In equilibrium, all firms with a higher (lower) production cost than $\gamma_{1}$ accept (reject) this offer. If firm 1 rejects the offer, it will signal that it is a low-cost firm which will lead the foreign firm and firm 2 to update their priors such that $E_{2}\left(c_{1}\right)=\gamma_{1} / 2$. Let $\phi_{2}$ denote the offer that the foreign firm makes to firm 2 after its first offer, $\phi_{1}$, is rejected by firm 1 . If firm 2 accepts the offer, $\phi_{2}$, firm 1 will have to compete against the foreign firm. Note that firm 1 observes the acquisition in this case and updates its beliefs such that $E_{1}\left(c_{2}\right)=0$. Equation (12) gives the expected profits: 


$$
\begin{aligned}
\Pi_{1}^{*} & =\left(\frac{2 a-\frac{\gamma_{1}}{2}-3 c_{1}}{6}\right)^{2}, \\
\Pi_{2}^{*} & =\left(\frac{2 a+\gamma_{1}}{6}\right)^{2} .
\end{aligned}
$$

Note that $\Pi_{1}^{*}$ given by equation $12 \mathrm{a}$ decreases with $c_{1}$, which confirms our sorting assumption that high (low)-cost firms accept (reject) the offer. There is a possibility that firm 2 rejects the offer. Let $\gamma_{2}$ denote the type of the firm which is indifferent between acceptance and rejection of the offer, $\phi_{2}$. If firm 2 rejects the offer, no acquisition will take place. The two local firms will compete against each other. In this case, firm 2 signals that it is a low-cost firm. Hence, firm 1 updates its priors such that $E_{1}\left(c_{2}\right)=\gamma_{2} / 2$. Accordingly, the expected profits are given by equation (13):

$$
\begin{aligned}
& \Pi_{1}^{*}=\left(\frac{2 a-\frac{\gamma_{1}}{2}+\gamma_{2}-3 c_{1}}{6}\right)^{2}, \\
& \Pi_{2}^{*}=\left(\frac{2 a-\frac{\gamma_{2}}{2}+\gamma_{1}-3 c_{2}}{6}\right)^{2} .
\end{aligned}
$$

This is a sequential Bayesian game, which we solve using backward induction. Hence, we start from the second stage of the game. In this stage, firm 2 should observe $\gamma_{1}$ as it is signalled by firm 1 rejecting the initial offer, $\phi_{1}$. Hence, $\gamma_{1}$ is determined in the first stage, and so is given in the second stage, denoted $\overline{\gamma_{1}}$. In equilibrium, firm 2 will accept the offer, $\phi_{2}$, if its realized production cost, $c_{2}$, is higher than the critical type, $\gamma_{2}$. Hence, firm 2's expected profit will be the offer, $\phi_{2}$, in the case of acceptance. This profit must be equal to its expected profit in the case of rejection, denoted $\Pi_{2}^{*}$, which is given by equation $(13 \mathrm{~b})$. Note that firm 2 will reject the offer only if its production cost is less than the critical type, 
$\gamma_{2}$. In equilibrium, the critical type is indifferent between acceptance and rejection. Expression (14) shows the indifference condition where $c_{2}=\gamma_{2}$ in equilibrium:

$$
\phi_{2}\left(\gamma_{2}, \overline{\gamma_{1}}\right)=\left(\frac{2 a-\frac{\gamma_{2}}{2}+\overline{\gamma_{1}}-3 \gamma_{2}}{6}\right)^{2}=\left(\frac{4 a+2 \overline{\gamma_{1}}-7 \gamma_{2}}{12}\right)^{2}
$$

This indifference condition immediately specifies the acquisition offer of the foreign firm in the second stage as a function of the critical type in the first stage, $\overline{\gamma_{1}}$, and the critical type in the second stage, $\gamma_{2}$. Clearly, $\phi_{2}$ decreases with $\gamma_{2}$. This stage is just like the one offer policy with one exception: firm 1 reveals that it is a low-cost firm - the second stage is viable if (and only if) firm 1 rejects the foreign firm's initial offer-which firm 2 would not have observed in the one offer policy. The lower the cost firm 1 signals, the smaller the profit firm 2 expects in the case of rejection. Hence, it is mainly the revelation effect which decreases the rejection profit. Furthermore,

$$
\phi_{2}\left(0, \overline{\gamma_{1}}\right)=\left(\frac{2 a+\overline{\gamma_{1}}}{6}\right)^{2} \leq \phi(0)
$$

The foreign firm may want to make a completely inclusive offer, $\phi_{2}(0, \cdot)$, to firm 2. As long as the foreign firm's offer in the first stage is not a completely exclusive offer, $\phi_{2}(0, \cdot)$ is less than the completely inclusive offer in the one offer policy, $\phi(0)$ (i.e., $\phi_{2}\left(0, \overline{\gamma_{1}}\right)<\phi(0)$ for all $\overline{\gamma_{1}} \neq 1$ ). If the foreign firm makes a completely exclusive offer in the first stage such that $\overline{\gamma_{1}}=1$-if there is no information revealed in the first stage - the second stage will be exactly the same as in the one offer policy because the second stage in the sequential offers case is the last stage that the foreign firm can make an offer. Hence, the one offer policy is a special case of the sequential offers case.

We are now ready to scrutinize the foreign firm's optimal second stage policy. Let $\Pi_{0}^{\gamma_{2}}$ denote the foreign firm's expected profit in the second 
stage, which we can write as a function of the critical type in the first stage, $\overline{\gamma_{1}}$, and the unilateral rejection rate in the second stage, $\gamma_{2}$ :

$$
\Pi_{0}^{\gamma_{2}}\left(\gamma_{2}, \overline{\gamma_{1}}\right)=\left(1-\gamma_{2}\right)\left(\left(\frac{2 a+\overline{\gamma_{1}}}{6}\right)^{2}-\left(\frac{4 a+2 \overline{\gamma_{1}}-7 \gamma_{2}}{12}\right)^{2}\right)
$$

Note that $\Pi_{0}^{\gamma_{2}}(0, \cdot)=0$. The first-order condition is given by equation (16):

$$
\frac{\partial \Pi_{0}^{\gamma_{2}}\left(\gamma_{2}, \cdot\right)}{\partial \gamma_{2}}=\frac{7}{144}\left(4\left(2 a+\overline{\gamma_{1}}\right)-2\left(7+8 a+4 \overline{\gamma_{1}}\right) \gamma_{2}+21 \gamma_{2}^{2}\right)=0
$$

which leads us to

Lemma 2 In the case of sequential offers, the foreign firm makes neither a completely inclusive nor a completely exclusive offer in the second stage.

\section{Proof.}

$$
\begin{aligned}
& \left.\frac{\partial \prod_{0}^{\gamma_{2}}\left(\gamma_{2}, \cdot\right)}{\partial \gamma_{2}}\right|_{\gamma_{2}=0}=\frac{7}{36}\left(2 a+\overline{\gamma_{1}}\right)>0 \\
& \left.\frac{\partial \prod_{0}^{\gamma_{2}}\left(\gamma_{2}, \cdot\right)}{\partial \gamma_{2}}\right|_{\gamma_{2}=1}=-\frac{7}{36}\left(2 a+\overline{\gamma_{1}}-\frac{7}{4}\right)<0 \text { because } a \geq 2 .
\end{aligned}
$$

From equation (16), we can derive a closed form solution for the optimal rejection rate, denoted by $\gamma_{2}^{*}$, which is a function of the critical type in the first stage, $\overline{\gamma_{1}}$ :

$$
\gamma_{2}^{*}\left(\overline{\gamma_{1}}\right)=\frac{1}{42}\left(\begin{array}{r}
-\sqrt{-336\left(2 a+\overline{\gamma_{1}}\right)+4\left(7+8 a+4 \overline{\gamma_{1}}\right)^{2}} \\
+2\left(7+8 a+4 \overline{\gamma_{1}}\right)
\end{array}\right) .
$$

In Figure 2, we illustrate the change in the unilateral rejection rate given by equation (17) with market size, $a$, and the critical type in the 


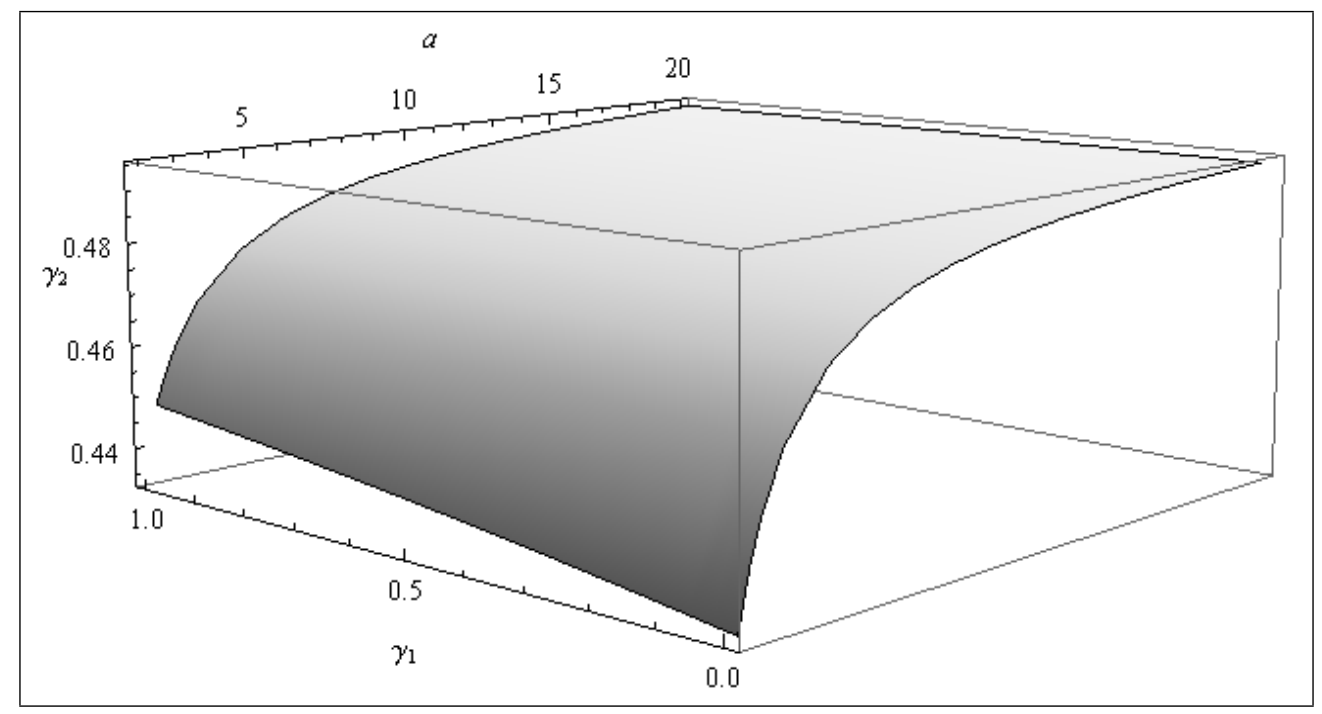

Figure 2: The Unilateral Rejection Rate, $\gamma_{2}\left(a, \overline{\gamma_{1}}\right)$.

first stage, $\overline{\gamma_{1}}$. Clearly, the unilateral rejection rate increases with $a$ and decreases with $\overline{\gamma_{1}}$.

We now turn to the first stage. Firm 1's expected profit in the case of acceptance is $\phi_{1}$. If firm 1 , however, rejects the offer, its expected profit is equal to

$$
\gamma_{2}^{*}\left(\frac{2 a-\frac{\gamma_{1}}{2}+\gamma_{2}^{*}-3 c_{1}}{6}\right)^{2}+\left(1-\gamma_{2}^{*}\right)\left(\frac{2 a-\frac{\gamma_{1}}{2}-3 c_{1}}{6}\right)^{2}
$$

In expression (18), the first part is the outcome if the other firm rejects the offer, which is equal to its probability $\gamma_{2}^{*}$ given by equation (17) times the expected profit of firm 1 competing against the other local firm. Similarly, the second part is the outcome if the other firm accepts the offer, which is equal to its probability $\left(1-\gamma_{2}^{*}\right)$ times the expected profit of firm 1 competing against the foreign firm. In equilibrium, firm 1 will accept (reject) the offer, $\phi_{1}$, if its realized production cost, $c_{1}$, is more (less) than the critical type $\gamma_{1}$. In equilibrium, firm 1's expected profit, $\phi_{1}$, in the case of acceptance must be equal to its expected profit in the 
case of rejection, given by expression 18. Hence, the critical type, $\gamma_{1}$, is indifferent between acceptance and rejection. Equation (19) shows the indifference condition where $c_{2}=\gamma_{2}$ in equilibrium:

$$
\phi_{1}\left(\gamma_{1}\right)=\gamma_{2}^{*}\left(\frac{4 a+2 \gamma_{2}^{*}-7 \gamma_{1}}{12}\right)^{2}+\left(1-\gamma_{2}^{*}\right)\left(\frac{4 a-7 \gamma_{1}}{12}\right)^{2}
$$

Substituting equation (17) into equation $(19)$ immediately specifies the foreign firm's acquisition offer in the first stage as a function of the firm types that will reject the offer. The foreign firm may want to make a completely inclusive offer, $\phi_{1}(0)$, to firm 1 such that

$$
\phi_{1}(0)=\left(\frac{2 a+1}{6}\right)^{2}=\phi(0) .
$$

Note that if the foreign firm makes a completely inclusive offer to firm $1, \gamma_{2}^{*}$ will be irrelevant as the foreign firm acquires firm 1 in the first stage of the game and competes against firm 2 with certainty. Consequently, the foreign firm does not learn anything about firm 2's profitability. Hence, there is no difference between the one offer policy and sequential offers as long as the foreign firm makes a completely inclusive offer to firm 1 . On the contrary, the foreign firm's first stage offer in the case of sequential offers is not as generous for any unilateral rejection rate such that $\gamma_{1} \neq 0$ which leads us to

Lemma 3 In the case of sequential offers, the foreign firm is more aggressive and offers a smaller compensation in the first stage than it would have offered to a local firm in the case of one offer to one firm.

Proof. We can rewrite $\phi(\gamma)$ given by (7) such that $\phi(\gamma)=$ $\gamma_{2}^{*}\left(\frac{4 a+2-7 \gamma_{1}}{12}\right)^{2}+\left(1-\gamma_{2}^{*}\right)\left(\frac{4 a+2-7 \gamma_{1}}{12}\right)^{2}$. Clearly, $\phi_{1}\left(\gamma_{1}\right)<\phi(\gamma)$ for any $\gamma_{2}^{*} \in(0,1)$ and $\gamma_{1} \neq 0$. 
It is the competition effect, which is not present in the one offer policy, that allows the investor to behave more aggressively. The intuition is simple: in the one offer policy, unlike when there are sequential offers, the foreign firm is not a possible threat to the firm receiving an offer, because this firm is certain that if it rejects the offer, it will compete against the other local firm.

We are now ready to scrutinize the foreign firm's optimal acquisition policy in the case of sequential offers. Let $\Pi_{0}^{\gamma_{1}\left(\gamma_{2}^{*}\right)}$ denote the foreign firm's expected profit which is given by equation 20 :

$$
\begin{aligned}
\Pi_{0}^{\gamma_{1}\left(\gamma_{2}^{*}\right)=} & \left(1-\gamma_{1}\right)\left(\left(\frac{2 a+1}{6}\right)^{2}-\phi_{1}\left(\gamma_{1}\right)\right) \\
& +\gamma_{1}\left(1-\gamma_{2}^{*}\right)\left(\left(\frac{2 a+\gamma_{1}}{6}\right)^{2}-\left(\frac{4 a+2 \gamma_{1}-7 \gamma_{2}^{*}}{12}\right)^{2}\right)
\end{aligned}
$$

where $\gamma_{2}^{*}$ and $\phi_{1}\left(\gamma_{1}\right)$ are given by equations $(17)$ and $(19)$, respectively. Note that $\Pi_{0}^{\gamma_{1}(\cdot)}(0)=0$.

Proposition 1 Sequential offers yield higher expected profits than the one offer policy.

\section{Proof. See Appendix A.1.}

The following remarks are in order before we proceed: first, there is no competition effect in the one offer policy; second, the revelation effect exists in both the one offer policy and sequential offers; finally, there is no risk of acceptance in either cases in that the firm receiving an offer is certain that the investor takes over the business so long as the firm accepts the investor's offer. 


\section{Optimal acquisition offers}

In the previous section, we have studied the case of sequential offers. In this section, we will determine the optimal acquisition policy and check whether the foreign firm can do better than sequential offers. Thus, we now turn to the case in which the investor makes a merger proposal simultaneously to both firms. In this case, the two local firms compete against each other if none of the firms accepts the foreign firm's merger proposal. If at least one firm accepts the merger proposal, the foreign firm competes against a local firm.

This case is of particular importance as it implies the possibility that both firms accept the foreign firm's merger proposal, but only one firm is picked by the foreign firm while the other firm reveals some information about its profitability. Any information which can be taken out of these decisions is symmetric, and it does not matter which firm is picked. Consequently, the investor flips a coin, and so each firm has the same chance of being picked.

We have to distinguish four different outcomes depending on acceptance and rejection of both firms. Note that firms cannot make their decision depending on acceptance or rejection of the other firm. Let $\gamma_{s}$ denote the critical type which is indifferent between acceptance and rejection. The following remarks are in order before we proceed: first, $\gamma_{s}$ is now relevant to both firms and not just to firm 1 as in the previous section; second, as discussed later, all firms with a higher (lower) production cost than the critical type, $\gamma_{s}$, accept (reject) the offer in this case as well.

Suppose that both firms accept the investor's offer. This outcome is a potential threat to each firm as it may not be the firm picked by the investor. Let the investor acquire firm 1 - as a result of tossing a coin - in such a situation. The investor updates its beliefs about the other firm's production cost because the acceptance of the other firm signals a highcost type. Hence, $E_{2}\left(c_{1}\right)=0$ as the investor takes over the business from firm 1 , and $E_{1}\left(c_{2}\right)=\left(1+\gamma_{s}\right) / 2>1 / 2$. If both firms accept the offer and 
firm 1 is selected, the expected profits are equal to

$$
\begin{aligned}
& \Pi_{1}^{*}=\left(\frac{2 a+1+\gamma_{s}}{6}\right)^{2} \\
& \Pi_{2}^{*}=\left(\frac{2 a-\frac{1+\gamma_{s}}{2}-3 c_{2}}{6}\right)^{2}
\end{aligned}
$$

There is also an asymmetric case with one firm accepting the offer and the other firm rejecting it. This has the opposite effect on the update of beliefs: the investor knows that only low-cost firms reject the offer. Let us consider the case that firm 1 accepts the offer, but firm 2 rejects it. Again, $E_{2}\left(c_{1}\right)=0$ due to the acquisition, but $E_{1}\left(c_{2}\right)=\gamma_{s} / 2<1 / 2$, leading to the expected profits given by equation 22 :

$$
\begin{aligned}
\Pi_{1}^{*} & =\left(\frac{2 a+\gamma_{s}}{6}\right)^{2} \\
\Pi_{2}^{*} & =\left(\frac{2 a-\frac{\gamma_{s}}{2}-3 c_{2}}{6}\right)^{2} .
\end{aligned}
$$

Finally, there is a possibility that both firms reject the offer. No acquisition will take place, but it is also not true that the game has not changed. Both firms know that the other one has rejected the offer because it is a low-cost firm, and hence $E_{2}\left(c_{1}\right)=E_{1}\left(c_{2}\right)=\gamma_{s} / 2$, leading to the expected profits given by equation 23 :

$$
\begin{aligned}
& \Pi_{1}^{*}=\left(\frac{2 a+\frac{\gamma_{s}}{2}-3 c_{1}}{6}\right)^{2} \\
& \Pi_{2}^{*}=\left(\frac{2 a+\frac{\gamma_{s}}{2}-3 c_{2}}{6}\right)^{2}
\end{aligned}
$$


The setup is now much more complex as each firm has to take into account all four outcomes. Let us consider firm 1. If this firm accepts the offer, denoted $\phi_{s}$, its expected profit given acceptance, denoted $\Pi_{1}^{A}$, is equal to

$$
\Pi_{1}^{A}\left(c_{1}\right)=\gamma_{s} \phi_{s}+\left(1-\gamma_{s}\right)\left(\frac{1}{2} \phi_{s}+\frac{1}{2}\left(\frac{2 a-\frac{1+\gamma_{s}}{2}-3 c_{1}}{6}\right)^{2}\right) .
$$

The first part is the outcome if the other firm rejects the offer, which is equal to its probability $\gamma_{s}$ times the acquisition price - the foreign firm acquires firm 1. If both firms accept this offer which happens with probability $\left(1-\gamma_{s}\right)$, two outcomes are possible: first, firm 1 is picked with probability 0.5 ; second, firm 2 is picked with probability 0.5 and firm 1 reveals that it is a high-cost firm. If firm 1 rejects this offer, its expected profit given rejection, denoted by $\Pi_{1}^{R}$, is equal to

$$
\Pi_{1}^{R}\left(c_{1}\right)=\gamma_{s}\left(\frac{2 a+\frac{\gamma_{s}}{2}-3 c_{1}}{6}\right)^{2}+\left(1-\gamma_{s}\right)\left(\frac{2 a-\frac{\gamma_{s}}{2}-3 c_{1}}{6}\right)^{2}
$$

The first part is the probability that firm 2 rejects the offer as well times the respective profit. The second part is the probability that firm 2 accepts the offer times the expected profit of firm 1 competing against the investor, which operates with zero production cost. Differentiation of $\Pi_{1}^{A}\left(c_{1}\right)$ and $\Pi_{1}^{R}\left(c_{1}\right)$ w.r.t. $c_{1}$ shows that

$$
\begin{aligned}
& \frac{d \Pi_{1}^{A}\left(c_{1}\right)}{d c_{1}}=-\frac{1-\gamma_{s}}{24}\left(4 a-6 c_{1}-1-\gamma_{s}\right)> \\
& \frac{d \Pi_{1}^{R}\left(c_{1}\right)}{d c_{1}}=-\frac{1}{12}\left(4 a-6 c_{1}+\gamma_{s}\left(1-2 \gamma_{s}\right)\right) .
\end{aligned}
$$

Expression (24) confirms that firms with a production cost lower (higher) than $\gamma_{s}$ reject (accept) the offer because acceptance profits decrease by less than the rejection profits when the production cost increases. 
In equilibrium, the unilateral rejection rate, $\gamma_{s}$, is determined by the indifference condition- $\Pi_{1}^{A}\left(\gamma_{s}\right)=\Pi_{1}^{R}\left(\gamma_{s}\right)$ - such that

$$
\begin{aligned}
\frac{1+\gamma_{s}}{2} \phi_{s}+\frac{1-\gamma_{s}}{2}\left(\frac{4 a-1-7 \gamma_{s}}{12}\right)^{2}= & \gamma_{s}\left(\frac{4 a-5 \gamma_{s}}{12}\right)^{2} \\
& +\left(1-\gamma_{s}\right)\left(\frac{4 a-7 \gamma_{s}}{12}\right)^{2} \Rightarrow \\
\left(1+\gamma_{s}\right) \phi_{s}=2\left(\gamma_{s}\left(\frac{4 a-5 \gamma_{s}}{12}\right)^{2}+\left(1-\gamma_{s}\right)\left(\frac{4 a-7 \gamma_{s}}{12}\right)^{2}\right) & -\left(1-\gamma_{s}\right)\left(\frac{4 a-1-7 \gamma_{s}}{12}\right)^{2} .
\end{aligned}
$$

From expression (25), we find that

$$
\phi_{s}(0)=\frac{8 a(2 a+1)-1}{144}<\phi(0) \text { and } \phi_{s}(1)=\phi(1)=\left(\frac{4 a-5}{12}\right)^{2} .
$$

Hence, the offer that makes the highest-cost firm indifferent between rejection and acceptance coincides for the one offer policy and simultaneous offers. However, the offer that includes all types, $\phi_{s}(0)$, is smaller compared to the one in the one offer policy. The intuition is that if the foreign firm makes a completely exclusive offer, it will be rejected with probability one, and it does not matter whether the offer is rejected only by one firm or by two firms. In any case, the local firms will compete against each other. If, however, the foreign firm makes a completely inclusive offer, it does matter whether the foreign firm makes the offer only to one firm or to both firms. Eventually, the offer will be accepted, so one local firm will have to compete against the foreign firm. The question is which firm will be competing against the foreign firm. If the foreign firm makes a completely inclusive offer only to one target firm, the other firm will compete against the foreign firm with certainty. Hence, there is no acceptance/rejection risk for the firm receiving this offer. If, however, the foreign firm makes this offer to both firms, the probability of competing against the foreign firm is 0.5 for both firms, which constitutes a potential threat to both firms. Consequently, both firms' reservation sale prices decrease. 
The expected profit of the foreign firm takes into account three different outcomes: first, both firms accept the offer, $\phi_{s}$, which happens with probability $\left(1-\gamma_{s}\right)^{2}$; second, one firm accepts the offer and the other firm rejects it, which happens with probability $2 \gamma_{s}\left(1-\gamma_{s}\right)$; and third, no firm accepts the offer, which happens with probability $\gamma_{s}^{2}$. In the first case, the foreign firm learns that the future rival is of high-cost type in the range between $\gamma_{s}$ and 1 . In the second case, it learns that the future rival is of low-cost type in the range between 0 and $\gamma_{s}$. In the last case, no offer is successful, so revealed information is irrelevant for the foreign firm as it stays out of the market - in such a case, only the target firms will make use of the revealed information and update their priors before competing against each other. The probability that the foreign firm pays the acquisition price, $\phi_{s}$, is equal to $\left(1-\gamma_{s}\right)^{2}+2 \gamma_{s}\left(1-\gamma_{s}\right)=\left(1-\gamma_{s}^{2}\right)$. Let $\Pi_{0}^{\gamma_{s}}$ denote the foreign firm's expected profit, which is given by equation (26):

$$
\begin{gathered}
\Pi_{0}^{\gamma_{s}}\left(\gamma_{s}\right)=\left(1-\gamma_{s}\right)^{2}\left(\frac{2 a+1+\gamma_{s}}{6}\right)^{2}+2 \gamma_{s}\left(1-\gamma_{s}\right)\left(\frac{2 a+\gamma_{s}}{6}\right)^{2}-\left(1-\gamma_{s}^{2}\right) \phi_{s} \\
=\left(1-\gamma_{s}\right) \times\left(\begin{array}{r}
\left(1-\gamma_{s}\right)\left(\frac{2 a+1+\gamma_{s}}{6}\right)^{2}+2 \gamma_{s}\left(\frac{2 a+\gamma_{s}}{6}\right)^{2} \\
-\left(1+\gamma_{s}\right) \phi_{s}
\end{array}\right), \quad(26)
\end{gathered}
$$

where $\left(1+\gamma_{s}\right) \phi_{s}$ is given by 25$)$.

Proposition 2 In equilibrium, sequential offers yield higher expected profits than simultaneous offers.

\section{Proof. See Figure 3 .}

As illustrated in Figure 3, the investor's equilibrium profits in both the case of sequential offers, $\Pi_{\text {seq }}$, and simultaneous offers, $\Pi_{\text {sim }}$, are increasing in market size, a. Clearly, the investor prefers sequential offers as it yields higher expected profits, for any market size, $a$.

Figure 4 illustrates the unilateral rejection rates in equilibrium, for all acquisition strategies. In larger markets, the unilateral rejection rate of 


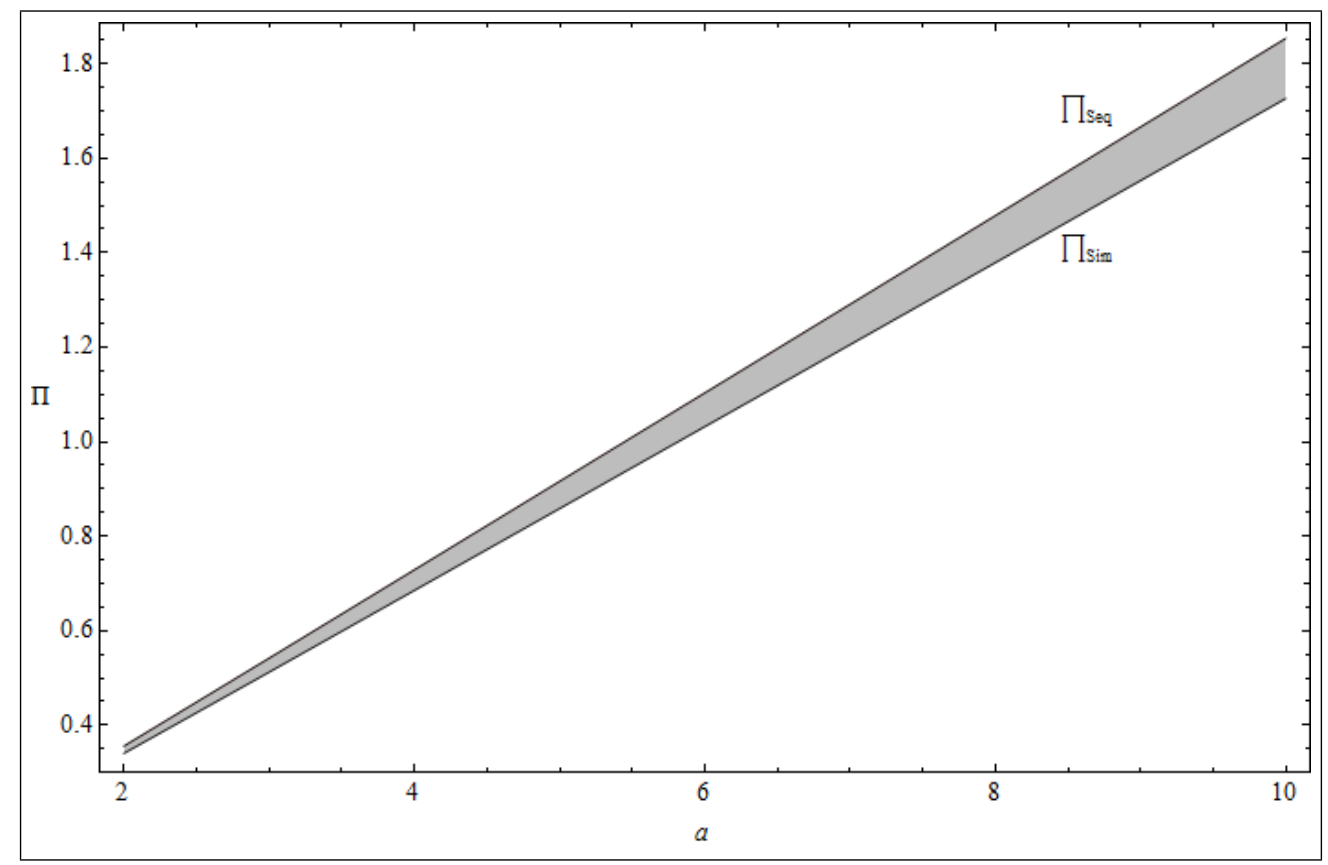

Figure 3: The Investor's Expected Profit (Sequential Offers vs Simultaneous Offers).

the firm receiving the first (second) offer in the sequential offers case is the highest (lowest). In the simultaneous offers case, the unilateral rejection rate is low compared to the sequential offers case, but high compared to the one offer policy. In sufficiently small markets such that $a=2$, the unilateral rejection rate in the one offer policy is the highest. Moreover, in smaller markets such that $a \in\{3,4\}$, simultaneous offers produce the highest unilateral rejection rate. The following remarks are in order before we proceed: first, the local firms expect to make low profits in smaller markets; second, a firm expects to make even lower profits if this firm competes against the lowest-cost firm - the foreign firm; third, there is a risk of acceptance if the foreign firm makes simultaneous offers; and lastly, because of this risk in the simultaneous offers case, the local firms are more reluctant to accept the foreign firm's offer in small markets.

The competition effect and the revelation effect exist in both the case of sequential offers and simultaneous offers. As already discussed, there is an additional effect in the simultaneous offers case, that is, the 


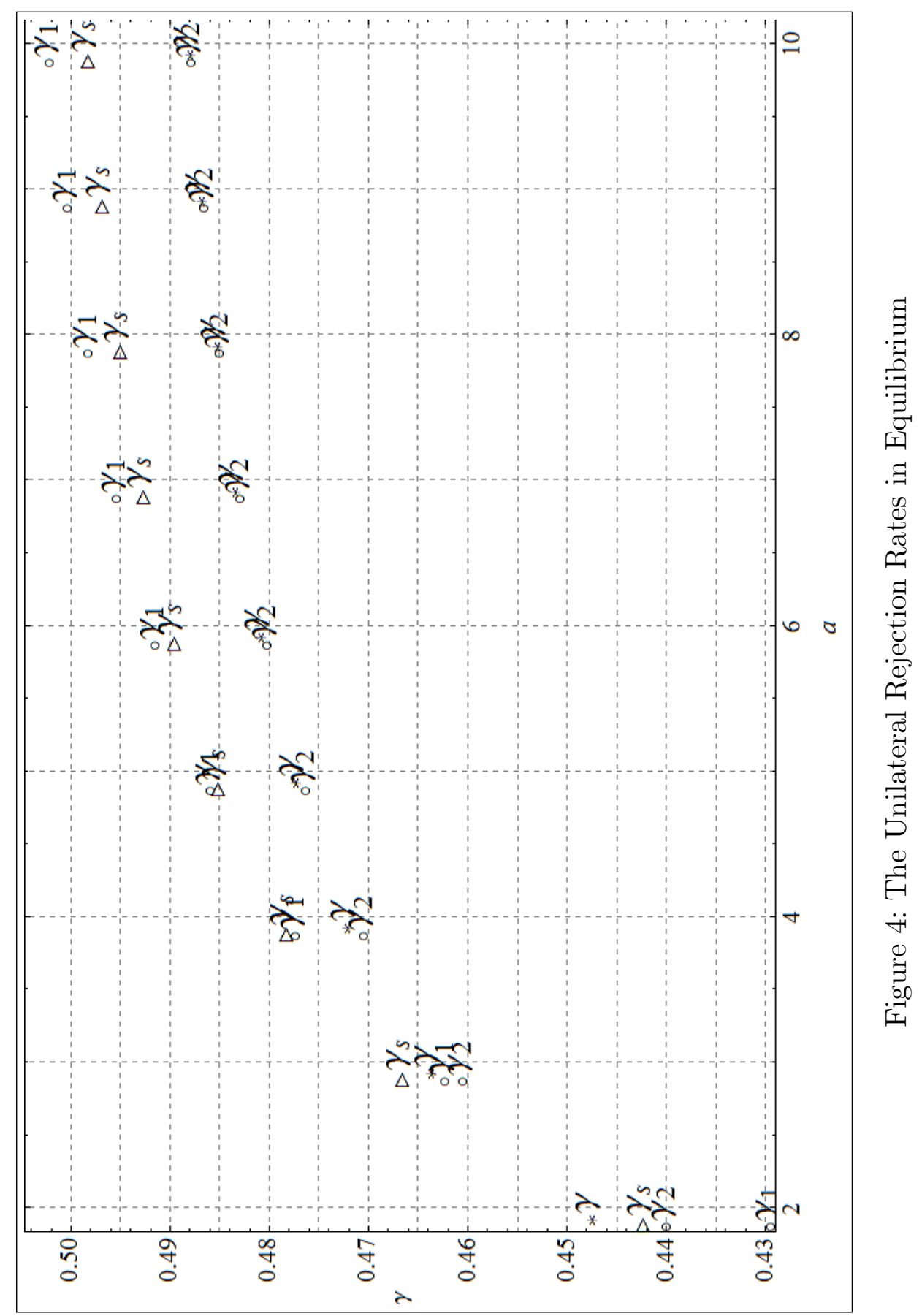


risk component. When there are simultaneous offers, a firm's acceptance of the investor's offer does not necessarily lead to the acquisition of that firm. It also depends on the other firm's acceptance and rejection of the same offer. When both firms accept the offer, there is a chance that the foreign firm acquires the rival firm. Hence, firms' expected profits in the case of acceptance are no longer equal to the offer, but the weighted average of the offer and the smaller outside profit.

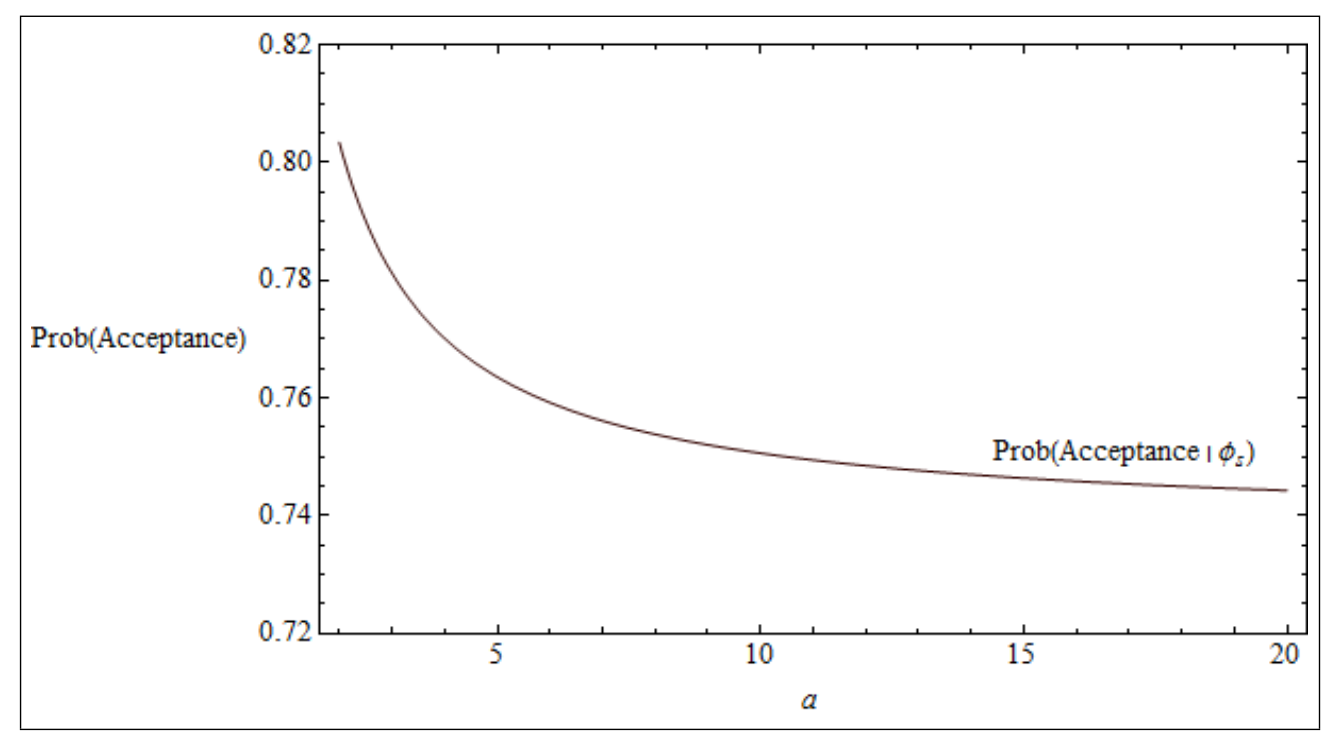

Figure 5: The Probability of Acceptance (Simultaneous Offers).

Proposition 3 Simultaneous offers yield higher expected profits than the case of one offer to only one of the two firms.

\section{Proof. See Appendix A.2.}

By making simultaneous offers to both firms, the foreign firm substantially improves the probability of acceptance as illustrated in Figure 5. The intuition is simple: even if one firm rejects the offer, there is still a chance that the other firm accepts it. Furthermore, as illustrated in Figure 6 , in equilibrium, the compensation that the foreign firm offers simultaneously to both firms is less than what it offers in the one offer policy. As is 


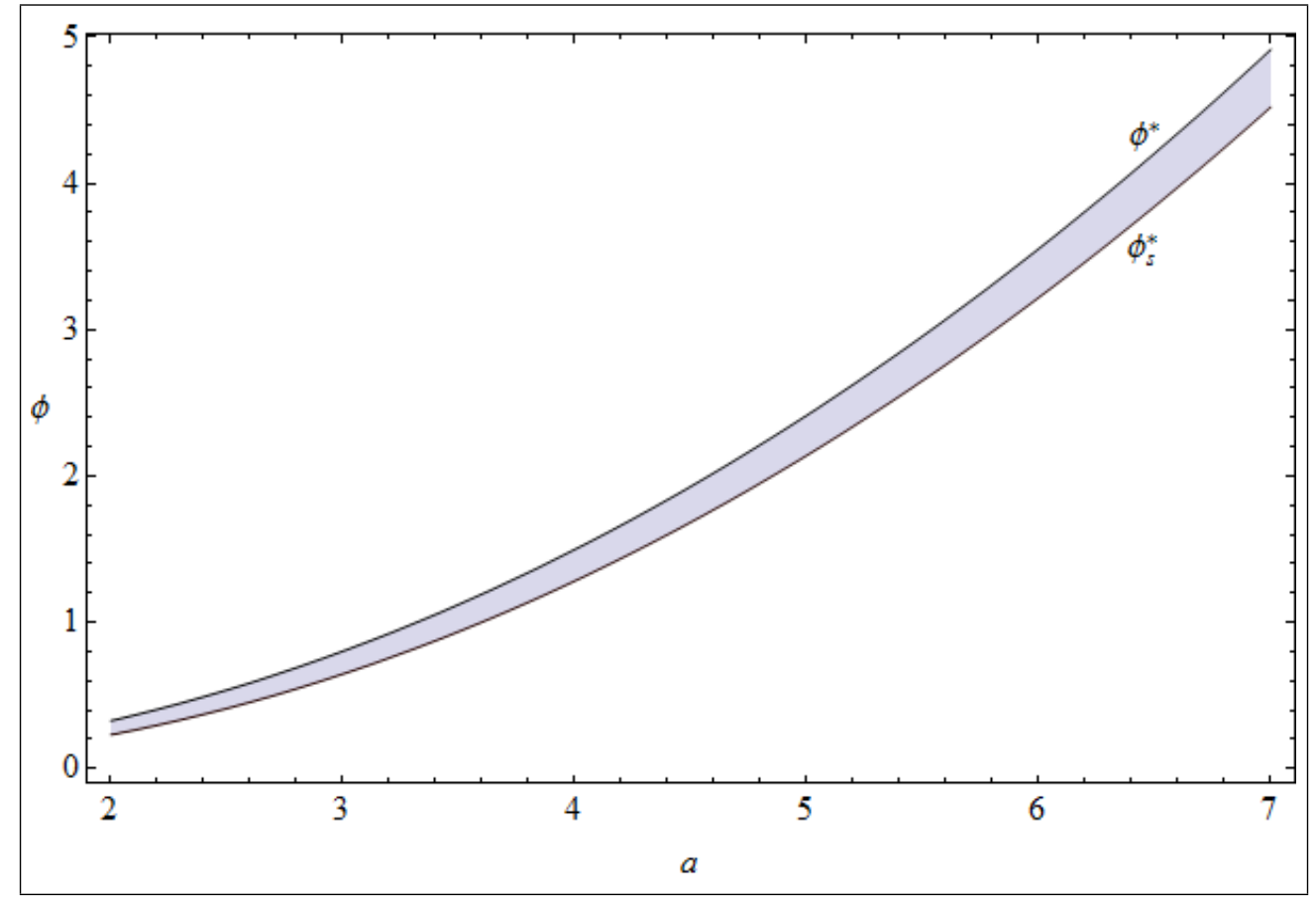

Figure 6: The Compensation (One offer vs Simultaneous offers).

clear from Figure 6, in both cases, compensation is an increasing function of market size, $a$. The results show that the foreign firm favors sequential offers compared to any other available take-it-or-leave-it acquisition strategy ${ }^{12}$

\section{Concluding remarks}

In this study, we endogenize negotiations between a foreign firm and target firms. We consider a foreign firm willing to acquire a local target firm in order to enter a host country market. We assume that the foreign firm does not know the local firms' production costs; hence, the foreign firm negotiates with the target firm(s) under incomplete information. In a two-

\footnotetext{
${ }^{12}$ Alternatively, the investor can ask the local firms to quote a price for which they will be willing to sell their business. However, a critical complication arises in such a situation, i.e., the investor cannot commit to a particular mechanism (see Appendix A.3).
} 
stage Bayesian game, we examine the foreign firm's optimal acquisition strategy within different take-it-or-leave-it acquisition strategies. We find that making one offer to only one of the targets is the foreign firm's least preferred acquisition strategy. It provides the foreign firm with the lowest probability of acceptance as the foreign firm relies on a single firm's decision. We show that the probability of acceptance substantially increases if the foreign firm simultaneously offers a merger proposal to the target firms. Our main result is that the case of sequential offers is the foreign firm's most preferred acquisition strategy. 


\section{Appendix A}

\section{A.1 One offer policy vs sequential offers}

Let us consider identical rejection rates for both the case of one offer to only one of the two firms and the case of sequential offers. Hence, $\widetilde{\gamma}=\gamma=\gamma_{1}$. We are able to rewrite the expected profits of the foreign firm as

$$
\begin{aligned}
\Pi_{0}^{\gamma}(\widetilde{\gamma}) & =(1-\widetilde{\gamma})\left(\left(\frac{2 a+1}{6}\right)^{2}-\phi(\widetilde{\gamma})\right) \text { and } \\
\Pi_{0}^{\gamma_{1}\left(\gamma_{2}^{*}\right)}(\widetilde{\gamma}) & =(1-\widetilde{\gamma})\left(\left(\frac{2 a+1}{6}\right)^{2}-\phi_{1}(\widetilde{\gamma})\right)+\Sigma,
\end{aligned}
$$

respectively, where $\Sigma=\widetilde{\gamma}\left(1-\gamma_{2}^{*}\right)\left(\left(\frac{2 a+\widetilde{\gamma}}{6}\right)^{2}-\left(\frac{4 a+2 \widetilde{\gamma}-7 \gamma_{2}^{*}}{12}\right)^{2}\right) \geq$ 0 . As we prove in Lemma 3, $\phi_{1}\left(\gamma_{1}\right)<\phi(\gamma)$ for any $\gamma_{2}^{*} \in(0,1)$ and $\gamma_{1} \neq 0$. Hence, $\phi_{1}\left(\gamma_{1}=\widetilde{\gamma}\right)<\phi(\gamma=\widetilde{\gamma})$ for all $\gamma=\gamma_{1}=\widetilde{\gamma} \in(0,1)$ implying that $\Pi_{0}^{\gamma_{1}\left(\gamma_{2}^{*}\right)}\left(\gamma_{1}=\widetilde{\gamma}\right)>\Pi_{0}^{\gamma}(\gamma=\widetilde{\gamma})+\Sigma$. Consequently, a foreign firm can always do better by making sequential offers than by adopting the one offer policy.

\section{A.2 One offer policy vs simultaneous offers}

Let us consider identical rejection rates for both the case of one offer to only one of the targets and the case of simultaneous offers. Hence, $\widetilde{\gamma}=\gamma=\gamma_{s}$. We are able to rewrite the expected profits of the foreign firm as

$$
\begin{aligned}
\Pi_{0}^{\gamma}(\widetilde{\gamma}) & =\frac{7(1-\widetilde{\gamma})}{144}(8 a+4-7 \widetilde{\gamma}) \widetilde{\gamma} \text { and } \\
\Pi_{0}^{\gamma_{s}}(\widetilde{\gamma}) & =\frac{1-\widetilde{\gamma}}{144}(8 a(1+\widetilde{\gamma}(8+5 \widetilde{\gamma}))+5+\widetilde{\gamma}(17-\widetilde{\gamma}(67-3 \widetilde{\gamma})))
\end{aligned}
$$

respectively. $\Pi_{0}^{\gamma_{s}}\left(\gamma_{s}=\widetilde{\gamma}\right)$ is larger than $\Pi_{0}^{\gamma}(\gamma=\widetilde{\gamma})$ if

$$
8 a\left(1+\widetilde{\gamma}+5 \widetilde{\gamma}^{2}\right)+5-\widetilde{\gamma}(11+3 \widetilde{\gamma}(6-\widetilde{\gamma}))>0
$$


Since $a>2$, this term is larger than $21+\widetilde{\gamma}(5+\widetilde{\gamma}(62+3 \widetilde{\gamma}))>0$. Consequently, a foreign firm can always do better by making simultaneous offers than by adopting the one offer policy.

\section{A.3 Auction}

In the context of incomplete information, employing an auction seems to be an attractive alternative compared to take-it-or-leave-it acquisition strategies. However, a critical complication arises if we employ an auction. We illustrate this complication in a first-price, sealed-bid auction.

Let the foreign firm run a first-price, sealed-bid auction. We will need a foreign firm that can commit to a particular mechanism. In the first-price auction, the foreign firm should commit to pick the lowest price offerthe bids in such a situation correspond to the acquisition price. If this commitment is lacking, the foreign firm may want to buy out the firm quoting the higher price, which implies that the auction is no longer a first-price auction. Let us assume that a price function, $\phi(c)$, exists in equilibrium which is monotonic and strictly decreasing in types, $c$ - the higher the production cost of the firm, the lower the price it quotes. If this price function exists, the price quoted by each firm perfectly signals its productivity. Hence, the profit of the foreign firm is equal to $\left(a+c_{2}\right)^{2} / 9-$ $\phi\left(c_{1}\right)$ after having acquired firm 1 , or equal to $\left(a+c_{1}\right)^{2} / 9-\phi\left(c_{2}\right)$ after having acquired firm 2. Let firm 1's production cost be lower than firm 2 's production cost (i.e., $c_{1}<c_{2}$ ). In such a case, firm 1 bids more in equilibrium (i.e., $\left.\phi\left(c_{1}\right)>\phi\left(c_{2}\right)\right)$ as we assume that the price function exists in equilibrium and is monotonic and strictly decreasing in costs. Given the above profit functions, it is obvious that the foreign firm's commitment may fail such that it prefers acquiring firm 1-the highest bidder - so long as $\phi\left(c_{2}\right)<\phi\left(c_{1}\right)<\phi\left(c_{2}\right)+\left(c_{2}-c_{1}\right)\left(2 a+c_{1}+c_{2}\right) / 9$. The intuition is simple: if the local firms' quoted prices are not too different, the foreign firm prefers to eliminate a strong rival from future competition by acquiring this firm and so to compete against a weak rival. 


\section{References}

[1] Banal-Estañol, A. 2007. Information-sharing implications of horizontal mergers. International Journal of Industrial Organization 25, 3149.

[2] Banal-Estañol, A., Seldeslachts, J. 2005. Merger failures. WZB Discussion Paper. No. SP II 2005-09. Berlin: Wissenschaftszentrum Berlin.

[3] Barros, P.B. 1998. Endogenous mergers and size asymmetry of merger participants. Economics Letters 60, 113-119.

[4] Borek, T., Bühler, S., Schmutzler, A. 2004. Mergers under asymmetric Information - is there a lemons problem?. University of Zurich, Socioeconomic Institute Working Paper 0213. Zurich: University of Zurich.

[5] Dassiou, X., Holl, P. 1996. Merger failure and merger profitability: an alternative to the Hviid and Prendergast model. Applied Economics Letters 3, 271-273.

[6] Deneckere, R., Davidson, C. 1985. Incentive to form coalitions with Bertrand competition. Rand Journal of Economics 16, 473-486.

[7] Farrell, J., Shapiro C. 1990. Horizontal mergers: an equilibrium analysis. American Economic Review 80, 107-126.

[8] Hennessy, D.A. 2000. Cournot oligopoly conditions under which any horizontal merger is profitable. Review of Industrial Organization 17, 277-284.

[9] Hviid M., Prendergast, C. 1993. Merger failure and merger profitability. Journal of Industrial Economics 41, 371-386.

[10] Kamien, M.I., Zang, I. 1990. The limits of monopolization through acquisition. Quarterly Journal of Economics 105, 465-499.

[11] Kamien, M.I., Zang, I. 1991. Competitively cost advantageous mergers and monopolization. Games and Economic Behavior 3, 323-338

[12] Kamien, M.I., Zang, I. 1993. Monopolization by sequential acquisition. Journal of Law, Economics, $\&$ Organization 9, 205-229.

[13] Perry, M.K., Porter, R.H. 1985. Oligopoly and the incentive for horizontal merger. American Economic Review 75, 219-227. 
[14] Qiu, L., Zhou, W. 2006. Product differentiation, asymmetric information and international mergers. Journal of International Economics $68,38-58$.

[15] Rodrigues, V. 2001. Endogenous mergers and market structure. International Journal of Industrial Organization 19, 1245-1261.

[16] Salant, S., Switzer, S., Reynolds, R.J. 1983. Losses from horizontal merger: the effects of an exogenous change in industry structure on Cournot-Nash equilibrium. Quarterly Journal of Economics 98, 185199.

[17] Stigler, G.J. 1950. Monopoly and oligopoly by merger. American Economic Review 40, 23-34.

[18] UNCTAD 2006. World Investment Report 2006: FDI from developing and transition economies - implications for development. New York and Geneva: United Nations.

[19] Zhou, W. 2008. Endogenous horizontal mergers under cost asymmetry. International Journal of Industrial Organization 26, 903-912. 